\title{
Foreword
}

John Dewey once said, "Philosophy recovers itself when it ceases to be a device for dealing with the problems of philosophers and becomes a method, cultivated by philosophers, for dealing with the problems of men."1 Dewey urged philosophers to get out of their armchairs and start their philosophizing from the problems people encounter in their lives. To do this well requires that they engage those already in the field who have devised diverse ways of studying people and their problems. Those studying the human condition through other modes also invariably draw on normatively freighted ideas that pose questions and difficulties that are frequent subjects of philosophical investigation. We - philosophers and non-philosophers - would do well to think together in our attempts to make sense of, and cope with, our predicaments.

In this spirit, and in the spirit of the Tanner Lectures themselves, the Philosophy Department at University of Michigan has long stressed the importance of inviting people from fields outside philosophy - including biology, classics, economics, history, law, literature, psychiatry, psychology, and sociology - to deliver the annual Tanner Lecture on Human Values. When, as chair of the Philosophy Department, I had occasion to invite the next Tanner lecturer, I noticed that the last anthropologist we had invited was Marshall Sahlins, in 2005. Since then, anthropology has turned ever more seriously to ethical dimensions of life - to the fact that people understand and deal with their condition not simply in terms of challenges to the

1 Dewey, "The Need for a Recovery of Philosophy (1917)," in The Essential Dewey, vol. 1, 68. 
satisfaction of their desires or the advancement of their interests but in ethical terms - as, for example, duties to fulfil, sins to avoid, and ideals to realize. I was therefore delighted to invite Michael Lambek, Professor and Canada Research Chair in the Anthropology of Ethical Life at the University of Toronto - and, as his title indicates, a leader in the anthropology of ethics - to deliver our 2019 Tanner Lecture.

Lambek draws on the work of several philosophers - including Stanley Cavell, Cora Diamond, Jonathan Lear, Alasdair MacIntyre, Gilbert Ryle, and Ludwig Wittgenstein - to explore the predicaments that arise in the ways people live with concepts, and with persons. He is particularly concerned with our ambiguous relations to "metapersons" - spirits, deities, demons, saints, and other human-like figures. It is far too easy to dismiss metapersons as unreal, and hence as concepts we should live without. Even atheists often relate to metapersons in fiction, drama, and history, and to currently existing humans reconfigured in our culture as metapersons - for example, pop-music idols and pro-wrestling personas. We fantasize about them, heroize and demonize them, write fanfiction about them, engage in cosplay. Concerns about their ontological status are often orthogonal to the varied ways engaging with metapersons animate ethical life.

While Lambek warns that it is too "heavy handed ... to describe metahumans as the anthropomorphization of concepts," that is not a bad starting place for considering one way we engage with them. Ethical concepts are often better contended with when we imagine how particular metapersons manifest them in particular circumstances than in the abstractions of philosophical analysis. When Christians ask, "What would Jesus do?"; when Hillary Clinton imagined conversing with Eleanor Roosevelt to help her think about how to face challenges in her life; or when audience members at a performance of Tennessee Williams's Cat on a Hot Tin Roof reflect on Brick's alcoholism to make sense of the addiction of one of their own family members, they engage with metapersons as guides to action and understanding.

Sometimes metapersons trouble us. We may feel haunted by ancestors with whom we had fraught relations - unforgiven wrongs, buried secrets, failures to communicate. Lambek seeks to illuminate the human condition by focusing on the case of Salim, a young man from Mayotte who is haunted not only by unfinished business with his suddenly deceased mother but by 
the spirits with whom his mother, a professional spirit-handler, engaged. The latter hound him in his dreams, demanding to strike up a relationship with him in accordance with their practice, upon the death of their handlers, of seeking cohabitation with the deceased's descendants. As a reformed Muslim, he regards them all as devils with whom it is sinful to interact, even if only to ask them to go away. One can be a good Muslim, or interact with spirits, but not both. Salim is also overcome with guilt at his failure to warn his mother against engaging with spirits, as doing so would send her to hell. Other Muslims in Mayotte have more easy-going relationships with various spirits, as longstanding local customs hold that only some are evil. Embracing a both/and perspective on the concepts informing their ethical lives, they see no conflict between being a good Muslim and engaging with spirits.

Lambek argues that Salim's troubles exemplify a type of ethical conflict that may arise for any persons whose lives are informed by incommensurable ethical concepts. Since nearly all of us inhabit societies that include multiple incommensurable ethical traditions informing our lives, Salim's troubles offer materials for reflection about our own. In Salim's case, the reformed Muslim concept of "devil" is incommensurable with the diverse concepts of spirits in local Mayotte culture. Lambek argues that, in regarding the latter as all devils and hence as commensurable with reformed Islamic notions, Salim makes a conceptual mistake. If we understand the meanings of concepts through their roles in language games - in how we live with them - we can understand Salim as taking a concept of spirits belonging to one language game and treating it according to the rules of another. Although he feels compelled to live strictly in accordance with reformed Islam and hence to repudiate traditional ways with spirits, he cannot repudiate the latter without experiencing turmoil - in part because repudiation also puts him in seemingly unresolvable tension with his deceased mother. ${ }^{2}$

2 It is as if, in the midst of an American football game, Salim catches the ball and starts playing with it according to the rules of rugby. Although he is dedicated to playing rugby exclusively, Salim finds that he cannot simply ignore the consequences of finding himself in a football game. 
As with all rich explorations of the human condition, Lambek's lecture raises more questions than it answers. His commentators ask many of them. Sherry Ortner, Distinguished Professor of Anthropology at UCLA, asks what more can be learned about Salim's predicaments, and our own, by further pursuing the metaphor of social life as a set of games. Jonathan Lear, John U. Nef Distinguished Service Professor at the Committee on Social Thought and Professor of Philosophy at the University of Chicago, asks how we might view Salim's troubles, and hence our own, by incorporating psychoanalytic, temporal, and developmental perspectives on his distress - considering how he may be misled by "motivated self-misunderstanding," how his interactions with Lambek might be a creative way for him to work through his mourning, and how taking an ironic perspective on the divergent expectations of the different traditions that inform his life might enable him to live well "with apparent contradictions." Joel Robbins, Sigrid Rausing Professor of Social Anthropology at the University of Cambridge, asks how we might better appreciate the merits of a life lived by an either/or logic such as Salim's, which insists on subsuming plural traditions under the ethical framework of a dominant one, in comparison to the life lived by a both/and logic, such as that of other denizens of Mayotte who accept both Islam and relations with spirits, and of anthropologists themselves.

It may be the case, as Lambek suggests, that making conceptual mistakes is inherent in the human condition, whether we live by a both/and or an either/or logic. If so, we need to ask the ethical question of how to live with such mistakes. Lambek's reflections illuminate the diverse challenges we face in answering this question.

\section{Elizabeth Anderson}

John Dewey Distinguished University Professor of Philosophy and Women's Studies, University of Michigan, Ann Arbor 